Universität zu Köln, Philosophisches Seminar, Richard-Strauss-Straße 2, 50931 Köln, Germany

[p] +49 (0)221 4701499 , [f] +49 (0)221470 8634

[e] markus.schrenk@uni-koeln.de, [w] http://www.clde.uni-koeln.de/schrenk

\title{
Is Proprioceptive Art Possible?
}

\section{MARKUS SCHRENK}

\section{ABSTRACT}

I argue for the possibility of a proprioceptive art (in addition to, for example, visual or auditory arts) where some aspects of some martial arts will serve as an example of that art form.

The argument starts with a thought by Ted Shawn, one of the pioneers of American modern dance: "Dance is the only art of which we ourselves are the stuff of which it is made." His idea can, in a first step, be successfully attributed to the martial arts and then be taken even further.

My argument adds two moves to Shawn's thought: (i) As martial artists, we might not only be the stuff the art is made of, but we may also be our sole audience because, (ii), we are, in such a case, not in the first place visual or auditorial observers (as common in painting or music or ballet) but introspective perceivers of our bodies and their movements:

As martial artists, we get the aesthetic pleasure fundamentally from proprioception and interoception. In this respect, we are essentially the stuff the art is made of and, also, necessarily our exclusive audience.

Keywords: Martial Arts, Art, Proprioception, Interoception

\section{$0 \quad$ OUTLINE}

The paper is organised in the following way. The first section deals with a couple of obvious objections and adds some caveats. The second section offers an explication of what I shall mean by art. Section three promotes the often neglected modality of proprioception and section four provides us with more detailed definitions of proprioception/interoception. While the previous sections serve as the necessary preliminaries, the part to follow, five, unfolds the actual argument for a proprioceptive art-form, starting with Shawn's quote as mentioned in the abstract. It 
introduces the aspects of martial arts, namely hyongs, katas, etc., that fulfil many of the roles of art as listed in section two. In the final, sixth, section the arguments will be wrapped up. (There's also a brief addendum on Schopenhauer's aesthetic theory and how it might relate to the martial arts. $)^{1}$

\section{CAVEATS}

(i) "Art" - at least in most of its meanings within the western history of art and aesthetic theories —is most certainly not the appropriate translation for the word "Do" as it appears, for example, in "Taekwon-Do" or "Karate-Do". Rather, the Japanese "Do" or Chinese "Dao/Tao" is more adequately, if still not entirely correctly, translated as the path or way of self-cultivation on which a pupil is usually accompanied by an authoritative master who teaches codified practices with normative force and supposed universal validity. ${ }^{2}$

Clearly, then, the so called "martial arts" are not art (as in "fine arts") just because they bear that name. The name does not even vaguely indicate that they might truly fall under that concept.

(ii) “... is art" is often meant to be a quality certificate: art is appreciated as a high cultural good and, thus, the label "art" is given, and often wrongly, as a quality measure. Here, no such value statement is implied when arguing for the art-character of martial arts. There's lots of bad art and there are many things in life that are highly valuable but clearly not artistic. ${ }^{3}$

(iii) Similarly, but to the opposite effect, the pejorative connotations of "martial" (from Mars, the Roman god of warfare) are: brutality, destruction, harm, and murder. Again, as in (i) and (ii), nomen non est omen.

(iv) Some martial arts are embedded in belief systems and religious practices such as Daoism, Confucianism, Hinduism, or Buddhism. For reasons of space I will, by and large, have to ignore the details of these connections (but see (Allen 2013) which examines this "dual cultivation of the spiritual and the martial" (Allen 2013: 242)).

(v) I have to restrict myself in all considerations to eastern martial arts, like Karate, Taekwon-Do, Kung-Fu, etc. It is from these arts that my sample cases come. (Medieval) European martial arts like, for example, sword fight, joust, or wrestling will be left out. 
(vi) The opposite is true for the concept of art for which western traditions will be my reference point. I turn to that concept now.

\section{WHAT IS ART?}

Within the western tradition of art, aesthetics, and art theory, there is, infamously, no universally accepted definition of what art is. No necessary and sufficient conditions an entity has to fulfil to count as a work of art seem entirely acceptable. (Gettier cases in epistemology are a finger exercise compared to the difficulties we face in case of a definition for art.)

Given the fact that there is no one strict definition of art that captures what our intuition (or that of other peoples or times, trans-historically and trans-culturally) subsumes under that concept, we might want to continue in a Wittgensteinian spirit: while artworks form a set of too diverse items as to be subsumed under necessary and sufficient conditions they nonetheless bear some family resemblance to each other. The locus classicus for such an approach is Morris Weitz' paper "The Role of Theory in Aesthetics":

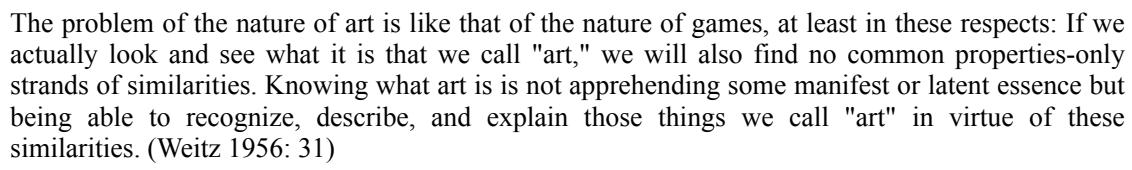

The problem of the nature of art is like that of the nature of games, at least in these respects: If we actually look and see what it is that we call "art," we will also find no common properties-only strands of similarities. Knowing what art is is not apprehending some manifest or latent essence but being able to recognize, describe, and explain those things we call "art" in virtue of these similarities. (Weitz 1956: 31)

I adopt the family resemblance theory of art as my reference point and I will explore my central thesis in terms of that theory. ${ }^{4}$

For that purpose, I will put forward a list of respects in which works of art family-resemble each other. Later, I will take this collection of properties and make credible that (some aspects of some) martial arts should count as a proprioceptive art because they match a substantial number of attributes on this resemblance list.

In the Stanford Encyclopedia of Philosophy entry on The Definition of Art, Thomas Adajian collects such a set of properties. I supplement the list Adajian initially offers by further aspects he mentions later in his article and also by my own considerations. ${ }^{5}$ Here, then, is the list of attributes 
no one of which is a necessary condition for being a work of art, but which are jointly sufficient for being a work of art, and which is such that at least one proper subset thereof is sufficient for being a work of art. (Adajian 2008)

\section{Artworks}

(I) possess positive, usually perceptual, aesthetic properties: typically artworks are arrangements that are intended to have the capacity to afford experiences of aesthetic character (cf. Beardsley 1982: 299), for example to invoke joy and pleasure;
(II) are expressive of emotion; ${ }^{6}$
(III) lack any practical use;
(IV) are potentially meaningful, i.e., have the capacity to convey complex by representational, mimetic, expressive, and formal properties;

(V) are formally complex and coherent;

(VI) are artefacts or performances which are the product of a high degree of skill and expertise;

(VII) sometimes have non-aesthetic, ceremonial or religious or propagandistic functions;

(VIII) are intellectually challenging;

(IX) exhibit an individual point of view;

(X) are original;

(XI) are the product of an intention to make a work of art;

(XII) belong to an established artistic form;

(XIII) are socially mediated. 
I wish to add two more entries. They are less self-explanatory and will be explicated below.

Artworks might

(XIV) be objects sanctioned by art schools;

(XV) bear resemblance to prototypes.

These two entries refer to theories of art that originally compete with the family resemblance approach. The latter, prototype theories of art, cf. (XV), focus not, or not initially, on lists of characteristic aspects in which artworks should resemble each other. Rather, they suggest that paradigm cases are picked out which definitely count as works of art ("If not this, nothing is art!"). Subsequently, all else is identifiable as work of art if and only if it resembles these exemplars. ${ }^{7}$ As I said, I will adopt the family resemblance theory for my purposes but I will occasionally refer to paradigm cases of art to point out that proprioceptive artworks share features of those prototypes. This is my reason to add entry (XV).

Conventionalist theories of art, cf. (XIV), deny that intrinsic features of an entity suffice (or even matter at all) to decide whether it counts as art. Rather, art is, in the institutionalist conventionalist theory, whatever the academy, museums, and artists get away with. Thus, “...is art” becomes an extrinsic, relational, sociological property (Cf. Danto 1981). Historical conventionalism, which focusses more on diachronic aspects rather than the synchronic sociological ones just mentioned, holds that artworks stand "in an art-historical relation to some set of earlier artworks" (Adajian 2008).

Conventionalisms, just as prototype theory, are typically not meant to supplement family resemblance theories but rather to oppose them. Still, I assimilate institutionalism into family resemblance theories in that I list "being an object sanctioned by art schools" as further entry (XIV).

I will show in section 5, especially 5.3, how the idea of a proprioceptive art (martial arts being my test case) fulfil many aspects of the supplemented family resemblance list.

Before I do that, I will first focus on the sense modalities art is usually appreciated with and I will introduce what is meant by proprioception. 
Of all human senses only the five outer senses—sight, hearing, taste, smell, and touch — get frequently mentioned. Often omitted are interoceptive modalities like proprioception (kinaesthetic sense), thermoception (temperature), nociception (pain).

Within the arts, an even smaller subset—hearing and sight— takes a clear priority. We are used to seeing paintings, photography, sculpture, or architecture, and hearing music or poetry. A mix of both seeing and hearing is realised in opera, theatre, and film.

Rarely, we are lucky enough to also touch the behind of a David or Venus cast or walk through and lean against the walls of some grand edifice. Yet, touch is at best secondary ${ }^{8}$ and hardly ever intended. ${ }^{9}$ Even less common are smell or taste. While some might be tempted to metaphorically call a chef an "artist" for her delicious food, most would still insist that cooking is, literally speaking, "only" a craft but not an art. There were attempts at smelling artworks: Alexander Nikolayevich Scriabin (1872 - 1915) created scent compositions to accompany his synaesthetic gesamtkunstwerk ${ }^{10}$, yet, arguably, this "art-form" never really kicked off. Proprioception (examples, as described in more detail in the next section, are the felt orientation of our limbs in space, muscle tensions, etc.) are not heard of as modalities for art appreciation.

There are, of course, practical reasons for our preference of sound and vision: the facility of reproduction and dissemination of the artworks, the possibility to enjoy the artworks at a distance, our relative excellence in the visual and auditorial faculties (as, for example, compared to our poor sense of smell), our acquired ability to converse with relative ease about the respective phenomena (as opposed to taste where almost only wine connoisseurs have gained the necessary vocabulary and expertise), etc.

There are also prima facie reasons against the proprioceptive senses: their intersubjective variance, their instability and irregularity. Yet, the appearance of intersubjective variance etc. is due to the fact that we tend to apply the wrong standards of comparison: it is true, in the same physical surroundings (an old masters exhibition, say) most of us have comparatively similar visual and auditory experiences (similar enough to talk about the canvases) while our proprioceptions might, in these same surroundings, intersubjectively vary and even change intrasubjectively from 
moment to moment. Yet, the right comparison is not bodies in the same outer physical surroundings (a museum, say) but bodies engaging in the same relevant proprioceptive art forms (let dance be an example for the time being; examples such as kata and hyong will be given later). Since we share a similar physique we can expect the proprioceptions to be sufficiently similar in everyone when engaging in the appropriate bodily moves and postures. ${ }^{11}$

There are, admittedly, the mentioned practical reasons for which the outer senses have been more popular and the inner senses have been neglected but these are no compelling in principle reasons why the inner senses cannot serve as a conduit for artistic appreciation.

Vision, hearing, etc. and proprioception/interoception all constitute their own sense classes ${ }^{12}$ and artworks could, in principle, be equally well made of compositions of proprioceptive sensations as of structures of visual or auditory phenomena. Or so I wish to claim in this paper: there is the possibility for proprioceptive art forms. ${ }^{13}$

To make a good case for proprioceptive art I turn to what proprioception exactly is.

\section{INTEROCEPTION, PROPRIOCEPTION}

Proprioception - from Latin proprius, one's own, and (re)ception —is the often (but by no means always) subconscious perception of stimuli within the body (including one's tendons, joints, muscles, skin) relating to spatial orientation, i.e., one's own position in space relative to the earth's centre; equilibrium ${ }^{14}$; one's movements, including acceleration (kinaesthesioception); one's posture, whether the body is moving with the required effort; internal conditions such as muscle tension, whether muscles are stretched or loose, etc.

Proprioception provides the parietal cortex of the brain with the necessary information it needs for bodily actions, the (re-)orientation of limbs and navigation. Proprioception is a feedback mechanism. That is, information about body moves is returned to the brain and updated during body movement, so that subsequent adjustments can, when necessary, be made. Proprioceptions, when permanently present (for example, the pressure of a chair we are sitting on), might be unnoticed because humans adapt to continuously present stimuli. This is known as habituation. 
Yet, the impairment of proprioceptive faculties results in deep deficits in our overall perception and action.

Often a sense of temperature (thermoception), of pain (nociception), even of time, is also mentioned, and, too, the awareness of our energy and stress levels, our state of well-being and our moods. One might want to speak more generally of interoceptions of which the latter perceptions and the above mentioned proprioceptions are two subsets. (For more detailed information on proprioception see, for example, the entry Proprioception in the Encyclopedia of Neuroscience (in bibliography as (Taylor 2009: 1143-1149)).

The following core section is dedicated to the idea of a proprioceptive art. It will be argued that martial arts as proprioceptive arts fulfil sufficiently many entries of the supplemented family resemblance list of section 2 .

\section{MARTIAL ARTS AS PROPRIOCEPTIVE ARTS}

\subsection{The StufF OF WhICH THE ART IS MADE}

In the abstract to this paper I said that Ted Shawn's claim-"Dance is the only art of which we ourselves are the stuff of which it is made"-is also true of the martial arts. ${ }^{15}$ Actually, in the sense of the claim Shawn intended - namely that dance is a visual art in which some of us are its material—many other performance arts, including happenings ${ }^{16}$, and also, for example, tattooing art fall under the "we are the stuff" label.

Yet, the disproved exclusivity of dance is not my issue here. Also, I will not argue that the martial arts can be listed amongst the visual arts where an audience watches a beautifully choreographed sequence of dance moves or, in our case, successions of punches and kicks. Probably martial arts can be visual art for much the same reasons I will give for my own goal but, again, that's not my concern here. Rather, I will argue that proprioception can be artistic and that some martial arts might be regarded as such proprioceptive arts.

A first step in this direction has been taken already: I have advertised the in principle possibility of proprioception being one of the modalities with which art may be perceived. Agreed, 
proprioception is a faculty which is not only underdeveloped in ordinary life: in art it is unheard of. And, yet, I will try to show now that some aspects of the martial arts can be seen as just that: a proprioceptive art form.

\subsection{Hyongs, Katas, AND other Prearranged Sequences of Martial}

\section{ARTS TECHNIQUES}

A martial artist might prove her accomplishments by breaking wooden boards or even bricks and stones with the bare power of her fists and the speed of her feet. Yet, it would be hard to argue that this, albeit amazing, skill can be seen as art (in a sense the western culture would accept).

Yet, many martial arts consist of a variety of practices amongst which the just mentioned power tests are only one. They also often comprise sparring, self-defence, and, crucial for my purposes, formal sets of fighting techniques, like hyong or poomse (Korean), katas (Japanese), or aka (Burmese). (Henceforth, I will, for better readability, speak of only hyongs and/or katas although all such forms of different martial arts are meant.)

These systematised routines are sequences or patterns of defensive behaviour, attacking techniques, steps and turnings, conducted in a strict order of movements while attempting to maintain perfect posture. These forms are practiced at various levels of mastery and get more and more elaborate and demanding the more experienced the martial artist becomes. Often, performances of hyongs, katas, etc. are key elements of grading ceremonies (e.g., to gain a blue belt in Taekwon-Do ${ }^{17}$ one has to master the seventh, 'T'oi-Gye', of the hyongs). Creative forms of hyongs and katas are possible although the established systematic, prearranged sequences dominate.

While the main objective of katas and hyongs is, often, to try out different techniques against virtual opponents in a safe environment which could ultimately be used to defeat a real opponent, this goal can become subordinate. Hyongs and katas can and are seen by many practitioners as performances in their own right. 
It is also important to mention that many of these venerable forms have a second semantic level next to their origin in combat. Their movements are not only defences and attacks, there's also often a layer of meaning that transcends the mere physical. In katas, for example, some numbers of moves (e.g. ' 108 '), have links to Buddhist spirituality ${ }^{18}$ and the movements of many hyongs quite explicitly designate spiritual concepts or virtues (cf. (Choi 1994: 351ff), (Kwon 1992: 75-78)):

- In Cheon-Ji hyong, low forearm blocks in all four directions point towards earth and four inner forearm middle blocks designate heaven ("Cheon-Ji” meaning heaven and earth).

- The cross shaped diagram the practitioner walks while performing the blocks and also the punches represents the four elements fire, water, air and earth. A Yin-Yang interpretation of Cheon-Ji hyong suggests itself.

- In both Toi-Gye and Yul-Gok Hyong their movement diagram represents the calligraphic character "scholar".

- Po Eun hyong's pattern is a straight line which designates Jeong Mongju's unsubduable loyalty to king and country ("Po Eun" being the pseudonym of Jeong Mongju who was a distinguished scholar of neo-Confucianism). Etc.

\subsection{HyONGS AND KATAS AS PROPRIOCEPTIVE ART ForM}

While a well conducted performance of a hyong or kata is a pleasure to watch it is an even greater joy to perform it oneself. This is not so much because one sees but, rather, because one feels what one does. ${ }^{19}$ Sometimes hyongs are a blindfolded exercise where the practitioner has to rely entirely on proprioception. Hearing the sounds of one's kicks and punches might be of some additional help, yet, most and crucial sensual input is given via proprioceptions and, while conducting a hyong, they are rich indeed: accelerations, angles, forces, overall speed, rhythm, effort, overcome resistance, strain, tension, stretch, pressure, gravity are all experienced during such a performance. If you "play" your body well, like a musician plays a sonata on her instrument, you have "harmonious" proprioceptions. Many factors, including precision, speed, the appropriate kinetics and mental and physical fortitude have to be in proper control: not any performance will lead to something aesthetic and it takes the practitioner a long stony way under the austere guidance of their master to learn the right movements with the correct intrinsic dynamics. Yet, again, just as a 
violinist hears when his performance is right the martial artist will, with enough practice, herself feel when her movements are correct. As with sonatas, it is then that proprioceptive pleasure is greatest.

\subsection{Art Checklist For the Proprioceptive ARt Form Hyong AND KatA}

A few hints have been given already why hyong and katas could count as performances of a proprioceptive art form: conducting such forms in established correct ways brings rich proprioceptive experiences with it which are, when the kata/hyong is performed well, felt with intense aesthetic pleasure.

Yet, aesthetic joy alone makes no art and, sometimes, art is everything else but pleasurable. A defence of martial arts as proprioceptive arts demands further arguments. They can be given in a straightforward way: we need only go through the family-resemblance list as introduced in section 2. If at least some (still better: a great number) of respects can be attributed to the proprioceptive experience of performed katas/hyongs then there is plausibility for them constituting proprioceptive art works. ${ }^{20}$

(To I) Possessing positive, usually perceptual, aesthetic properties. This entry has been taken care of in (5.2): the muscle tension and spatial position of one's leg felt in a precise, head high kick, a punch with ideal acceleration and deceleration, a gravity defying $360^{\circ}$ rotating jump, i.e., the positive proprioceptive "feel" that a correctly conducted kata/hyong induces has, undeniably, perceptual aesthetic properties. ${ }^{21}$ To these do not only belong pleasure but also wonder, appreciation, and awe: think of the marvel when a new inner bodily experience arises which one has not undergone before or the surprise about the possibility of an unfamiliar arm or leg movement. ${ }^{22}$

(To II) Being expressive of emotion. Hyongs can be performed in meditative ways as much as with almost brutal force and speed. One can pause, hesitate, speed up, explode, hold one's head proudly up in the air, look down, etc. There's no prima facie reason why the width of emotions that can be expressed in katas is not as wide as in dance. If one performs the kata alone the emotions are, of course, by and large expressed interoceptively. 
(To III) Lacking any practical use. Undeniably, katas and hyongs can be utilised effectively to practice attacks and defences and, thus, imitate real combat. In fact, this is their original purpose. Yet, also pre-renaissance religious art, for example, used to have clearly circumscribed "practical" purposes - worship, contemplation, education, etc.- but ceased to have these purposes. Actually, today, these roles are often forgotten and, clearly, the appreciation of, say, annunciations and crucifixions is possible while no religious practice is thereby exercised. This might well be or become true of proprioceptions: feeling the muscle tension accompanying a head high kick might not anymore be connected to a winning strike. Thus, hyongs and katas, just as other prototypes of art (cf. entry (XV)), too, have lost or, at least, may lose their original practical use.

(To IV) Being potentially meaningful, i.e., having the capacity to convey complex meanings by representational properties. One can argue in two ways for the meaningfulness of hyongs and katas. (i) Relating to these forms' initial purpose of virtual combat the felt proprioceptions are (potentially) meaningful in that they could stand for attacks and defences. (ii) Some performed combat patterns also represent yin/yang, indomitable loyalty, etc. as shown above.

Following up on (III), katas share the mere potential meaningfulness with, for example, the religious paintings mentioned: that the lilies in Fra Angelico's Annunciation frescos in Florence's St. Marco Monastery stand for Marie's virginity might not be known to someone today who can nonetheless appreciate the balanced figures, harmonious colours, the calm and minimal composition. In fact, everyone unfamiliar with the Christian doctrine might not even know who is depicted and why, yet, still enjoy the beauty of Fra Angelico's works.

The same holds for katas and hyongs (again cf. the prototype entry (XV). A disciple of the martial arts might well not be interested at all in the martial aspects of her art or the philosophical principles (yin/yang) expressed and still enjoy the coherent composition of proprioceptions in abstraction from any reference to fight or philosophy.

(To V and VI) Being formally complex and coherent; being an artefact or performance which is the product of a high degree of skill and expertise. The complicated sequential patterns of hyongs and the fairly high bodily physical demands speak for themselves here. 
(VII) Sometimes having non-aesthetic, ceremonial or religious or propagandistic functions. Again, these are self-explanatory features (for propagandistic features, cf. my remark on Po Eun hyong in IX).

(VIII) Being intellectually challenging. Performing hyongs is not only physically but also intellectually demanding. It is not at all easy to memorise the formally complex patterns that become more and more labyrinthian the higher one's grading.

Yet, this might not be meant by (VIII). Rather, it is the intellectual challenge an artwork poses to the perceiver, not the artist. Here, we encounter probably the first aspect in the family resemblance list that is not fulfilled by the proprioceptive awareness we have as artist and, simultaneously, as our own audience while performing a hyong. It seems that for us as audience (not as performer) there is not only little intellectual challenge, there is not even an intellectual process involved at all.

Luckily, this is no problem for a theory of family resemblance as it does not comprise a list of necessary features. Also, notice that a lack of intellectual challenge is fairly common and, thus, shared with other prototypes of art (cf. XV): while most modern "classical" music (latest after Schönberg, Berg, Webern, etc.) does present such a challenge, earlier classical music might not and, thus, can be enjoyed with no mental effort whatsoever.

(To IX) Exhibiting an individual point of view. Again, this is a feature not shared by martial arts. Personal emotions might be felt (cf. I) and expressed (cf. II) but a stance regarding some political, philosophical, or some other public issue is hardly expressible when performing katas.

Having said that, one can imagine situations in which this is possible: take again Po Eun hyong which represents loyalty to king and country. If you perform it in front of the king (or refuse to) you might well express an individual point of view. Note, however, that this would be a visual performance, not the proprioceptive one I am here after.

It is also worth noting that individualism is a highly liberal, western ideal to which eastern arts do not necessarily subscribe..$^{23}$

(To X) Being original. With conductors and musicians performing pieces of classical music martial artists share that they "only" interpret a preexisting score. The hyong's originality just as the music 
score's lies, so one could claim, first and foremost in the grandmaster's or composer's genius. Yet, clearly, also interpretations can be highly original as the $\mathrm{CD}$ market for new Bach, Beethoven or Beatles recordings attests to.

Also, although not encouraged in all martial arts, there are creative forms of hyongs where the novel, unconstraint, artistic composition of movements is allowed to the practitioner.

(To XI and XII) Being the product of an intention to make a work of art; belonging to an established artistic form. These features are possibly not (yet) possessed by hyongs and katas but, hopefully, they will be if there is a potential for proprioceptive art works.

(XIII) Art is socially mediated. Proprioception, necessarily being a private experience, is elusive and difficult to communicate. As a solitary enterprise, is, thus, proprioception not totally inapt to form a basis for socially mediated art? Well, just as not any arbitrary visual input one enjoys privately is art so is not any proprioception. In the possible paradigm cases I have introduced, katas and hyongs, the expertise to create artistic proprioceptions is and has to be acquired through one's master's teachings. Not just any odd movement and the caused proprioceptions constitute a proprioceptive artwork. Only those that have the right score, the right structure, the right harmony. For these reasons, discourse about proprioceptive art is not only possible but necessary. Public and social sets of rules, sets of expectations, the possibility of mistake, correction and critique do exist. (XIV) Objects sanctioned by the art schools. The two entries, XI and XII, considered above also relate to the theory of art, conventionalism, that is under concern here in (XIV). Yet, in the martial arts, there is no established self-description as being artistic (in the western sense of art) and, so, there is no convention or historic tradition yet. Thus, it has to be acknowledged that conventionalism in both its institutional and historical form is not quite the right theory of art to capture hyongs' and katas' artfulness.

(XV) Bearing resemblance to prototypes. We are much better off concerning (XV), the similarity to prototypes: I have frequently referred to paradigm cases of art and pointed out their resemblance to hyong and kata. Sure, my reference to samples of arts of a very different kind only helps to an extend because the mode of perception I advertise for martial arts, proprioception, is radically different from the sense experiences we have of the prototypes mentioned but many structural and 
semantic features are shared as has been seen in the case of performances of symphonies, sonatas, etc. and the religious art of pre-renaissance Europe.

\section{EVALUATION}

If what has been said here is an argument for hyongs and katas being art it is most probably not only an argument for them constituting a proprioceptive art but also for them being a visual art. Why, again, my focus on proprioception? I have two substantial and one mere psychological reasons. I also have a missionary aim.

The psychological reason is that Ted Shawn's quote invites us to consider that further step: from being the stuff the art is made of to the embodied perception and internal joy of what that stuff does. For, why should the aesthetic perception of our bodies be restricted to its vision if we can enjoy direct, immediate interoception as well?

The first of the more substantial reasons is that there is, as a matter of fact, often no other audience than oneself when performing katas. Yet, oneself is mainly an internal proprioceiver of one's body, not a seer or hearer of its movements.

The second reason is that an even greater joy of such a performance emerges from the proprioceptive awareness of it than it does from vision. Take, for example, the felt correctness of a kick or punch: the right position of one's leg in space, the accurate acceleration, the precise muscle strain, etc. is proprioceptively an even greater pleasure than it is visually.

While many auditory and visual arts affect the intellect more than the emotions (or, at least, emotions only mediated through the intellect), a proprioceptive art would be directly in touch with one's feelings.

Finally: just as, for example, the impressionists and cubists taught us new ways of seeing, the martial arts could teach us an entirely novel way to perceive artistically: to feel and perceive our bodies from within. Here, we'd find a positive affirmation of being embodied creatures. That's the normative, missionary part of my claim. 
Two problems remain to be discussed. (i) What's actually the artwork, i.e. the entity, in the case of hyongs? I have no answer. Yet, this ontological problem is far from being solved when considering, for example, music: is it the score, the performance, the sound waves, or whatever unfolds in the audience's mind? So, I don't feel too bad having no solution to this problem.

(ii) Is the argument not a slippery slope along the lines of Joseph Beuys' "Alles ist Kunst, jeder ist ein Künstler" (Everything is art. Everyone's an artist.) Would, for example, a sex-worker's performance on one's body, where intense proprioception is secured, be art? Maybe not because his or her actions do not transcend the pleasure they give. They are not grown out of a practice that used to bear meaning and still potentially does. If however, such meaning can be given to the sexual acts—arising from a kind of ritual, for example — and many more of the checklist entries can be met then there is probably no reason why sex-work could not become an art where a small audience, possibly just one person at once, is attending the artist's performance. ${ }^{24}$ Similar considerations might hold mutatis mutandis for massage, and also crafts that relate to other than the proprioceptive senses, like cooking or, maybe, perfume symphonies. ${ }^{25}$

I should say that I would not welcome the consequence that everything is art, for then nothing really is. Yet, unlike Shawn for dance, I also do not wish to claim exclusivity for martial arts as proprioceptive arts.

\section{SUMMARY}

I have suggested in this paper to view certain aspects of martial arts as proprioceptive art forms. What I hope to have achieved at least is to have enticed the reader to give the idea of proprioceived works of art further thought. If this has happened the space of possible sense perceptions that might constitute art has been further illuminated. What I hope to have achieved at best is to have convinced some readers that the previously shadowy areas in that space of possibilities are not empty: performances of katas and hyongs are such proprioceptive art forms. 
Abell, Catharine 2011 'Art: What it Is and Why it Matters', in Philosophy and Phenomenological Research. Early view online version (21. Jul. 2011) published before inclusion in an issue.

Adajian, Thomas 2008 The Definition of Art $\mathrm{n}$ The Stanford Encyclopedia of Philosophy (Fall 2008 Edition), Edward N. Zalta (ed.), URL $=<$ http://plato.stanford.edu/archives/fall2008/ entries/art-definition/>

Allen, Barry 2013 Games of Sport, Works of Art, and the Striking Beauty of Asian Martial Arts Journal of the Philosophy of Sport, Vol. 40, No.2, pp. 241-254.

Beardsley, Monroe 1982 The Aesthetic Point of View Ithaca, New York: Cornell University Press

Carnap, Rudolf 1998 Der logische Aufbau der Welt Meiner

Choi, Hong Hi 1994 Taekwon-Do Dreieich Budo-Verlag, Sport-Rhode

Danto, Arthur 1981 The Transfiguration of the Commonplace Harvard University Press

Elcombe, Tim L. 2012 Sport, Aesthetic Experience, and Art as the Ideal Embodied Metaphor Journal of the Philosophy of Sport (Special Issue: Sport and Aesthetics) Vol. 39, No. 2, pp. 201-217

Eliade, Mircea 1954 /2004 Yoga Insel (Original: Le Yoga. Immortalité et liberté, Paris, Payot, Bibliothèque scientifique).

Kwon, Jae-Hwa 1992 Zen-Kunst der Selbstverteidigung. Taekwon-Do-Karate O. W. Barth

Mach, Ernst 1897 Contributions to the Analysis of the Sensations The Open Court Publishing Company

Mishima, Yukio 1970 Sun and Steel: Art, Action and Ritual Death Grove Press

Weitz, Morris 1956 The Role of Theory in Aesthetics The Journal of Aesthetics and Art Criticism, Vol. 15, No. 1, pp. 27-35

Schopenhauer, Arthur 1969 The World as Will and Representation Dover Publications Sparshott, F. 1995 A measured pace: Toward a philosophical understanding of the arts 
of dance. Toronto: University of Toronto Press

Taylor, J.L. 2009 Proprioception Encyclopedia of Neuroscience Larry R. Squire (ed.), La Jolla,

California, USA, pp. 1143-1149

\section{AdDENDUM: “The Blessedness OF WiLl-Less PerCePtion”}

While, in this paper, I can, for reasons of space, clearly not do justice to Arthur Schopenhauer's theory of art I still wish to hint at the fact that one might well find arguments for why proprioception and the martial arts can be treated as art forms in his aesthetics.

For Schopenhauer, aesthetic perception is one way in which the will-tormented subject can achieve tranquillity. Remember that the will is, for the author of The World as Will and Representation, the blind raging force ("Willing as a whole has no end in view." (Schopenhauer 1818: 165)) that makes the world, including us humans, move. There's nothing much positive about the will, as it is equally destructive as it is creative. Moreover, we are helpless victims of its "endless striving” (Schopenhauer 1818: 164) and capable of directing or countering it only to a very small degree. The best we can do to transcend this sad human condition is to try to calm this restless will in us. Amongst three ways to do so-asceticism in order to destruct the strained ego and selfless moral pity being the other two-aesthetic perception can serve this purpose. For, in aesthetic appreciation, which is a non-utilitarian pleasure, we may lose ourselves in the artwork and leave our individual ${ }^{26}$, purpose bound will behind. Schopenhauer sees architecture, sculpture, painting, poetry, and especially music (opera) as paradigm means to reach such a pure and will-less state of mind and he speaks of "the blessedness of the will-less perception" (Schopenhauer 1818: 198). His theory is, thus, not so much a definition of art but rather a description of what it can achieve when it's at its best: the dissolution of the self in order to escape the straying will's claws.

Famously, Schopenhauer has been heavily influenced by Hindu and Buddhist thought and, so, it comes as no surprise that his theory of art might be used as a bridge between the eastern martial arts" "do" and the western "art". For, like yogic practice ${ }^{27}$, hyongs and katas can also be used as meditative self-dissolution techniques. Their physical aspects, the proprioception of our bodies' postures, movements, energy levels, etc., can be means to a better self-perception which is initially 
needed to ultimately overcome one's self. In the martial arts, Schopenhauer's aesthetics could come close to his ascetics. Thus, seen in a Schopenhauer-esque way, performed hyongs may serve the double purpose of western art and eastern do. 
${ }^{1}$ I wish to thank Sabum Nim Thomas Weiss for having taught me how to enjoy the aesthetic pleasures of the proprioceptive art of Taekwon-Do. Thanks are also due to Rudolph Glitz, Philipp Hübl, and Claudia Flasdieck who have discussed earlier drafts with me and to an anonymous referee for the abundance of highly valuable comments. Tim Steeger helped me with the bibliography. Needless to say, the flaws that still remain are entirely my own responsibility. For the countless inspirations regarding all topics related to the paper's subject I am infinitely grateful to C.

${ }^{2}$ A further interpretation of "do" could be the Greek "techné”. (Thanks to Philipp Hübl for this hint.)

${ }^{3}$ A discussion on whether already the definition of art should include value judgements can be found in (Abell: 2011).

${ }^{4}$ There are, of course, competing approaches to art, such as prototype theory and conventionalism. I will come back to these accounts briefly.

${ }^{5}$ I claim no originality for these entries. Almost all aspects are inspired by (Adajian 2008).

${ }^{6}$ (I) and (II) need to be distinguished: artworks might invoke experiences of emotions like joy as in (I), i.e., these are emotions one actually feels when perceiving the artwork, and, (II), they might be expressive of an emotion, i.e., they might refer to an emotion like anger. Here, it is not essential that the perceiver actually feels that emotion. It is enough if they are aware of the reference to that emotion.

${ }^{7}$ A potential way to criticise prototype theory is to say that, since everything resembles everything else in some respect, one has to further specify the correct or right ways in which novel cases have to be like the paradigms. A catalogue of typical features seems necessary to be able to decide. Thus, prototype theory might want to refer to lists found in family resemblance theories.

${ }^{8}$ Touch plays a huge role in design, of course, where the door knob, the chair, the touchpad, etc. have to have the right feel to them, but, still, there's no art form here that corresponds to touch as obviously as painting corresponds to vision. A case for design being art could possibly be made, yet, I wish to remain neutral on this issue here.

${ }^{9}$ With the possible exception of art movements such as Fluxus where the physical interaction with the artworks was encouraged.

${ }^{10}$ Scriabin planned his work Mysterium to exploit the senses of smell and touch as well as hearing. Cf.: http:// en.wikipedia.org/wiki/Mysterium_(Scriabin)

${ }^{11}$ Sure, each of us has different physical abilities and attributes so that some differences in proprioceptions will result. Yet, this is no deviation from the faculties of sight or hearing.

${ }^{12}$ Strikingly, the empiricists, early and modern, list all sensations, including proprioceptions, as equal in "the given" (although they then frequently focus primarily on sight and hearing). Cf.: (Carnap 1928: $\S \S 76,85,131,133$ ), (Mach 1897: §5\&10 of Introductory Remarks, p10/18).

${ }^{13}$ Referring especially to Dewey, Tim Elcombe highlights the pragmatists' embodied notion of aesthetics, i.e. their insistence that the body is in its entirety, with all its senses including kinesthetic sensations, essential for aesthetic experiences: "The lived body thus [...] is irreducibly the medium we use to wholly transact with the world and gain an aesthetic, value-laden awareness of our existence." (Elcombe 2012: 206) This somewhat points to the possibility of a proprioceptive art.

${ }^{14}$ Especially the vestibular system of the inner ears is responsible for equilibrioception: the sense of angular momentum and linear acceleration, including gravity. Thus, the vestibular system is essential to attain and maintain postural equilibrium and balance.

15 There are other similar claims about dance that are also true of the martial arts. Barry Allen quotes Francis Sparshott, a philosopher of dance: "nothing is more characteristic of dance than the way it is energized; in learning an exotic dance style, what one has principally to master is how and where the energies go' (Sparshott 1995, 108)" (Allen 2013: 248 ) and then continues to point out that that is correct for out topic, too. However, I should mention that Allen points out differences to dance and art, too, one of them being that "dance movements are endotelic, but more, they look endotelic. The beauty of martial arts movements has a different basis, since these movements are trained under a regime antithetic to endotelic value. The aesthetic quality of martial arts movements comes from their purposiveness, their instrumental effectiveness. Aesthetic quality is a byproduct of real efficacy." (Allen 2013: 250)

${ }^{16}$ Yves Klein's Anthropométries, for example, where he uses naked female models, covered in International Klein Blue paint, as "brushes".

17 That is, in Kwon, Jae-Hwa's traditional Taekwon-Do (cf. Kwon 1992). 
${ }_{18}$ Many Buddhists believe that there are 108 defilements a person must overcome to achieve enlightenment. Malas (rosaries) usually have 108 beads and temples 108 steps.

${ }^{19}$ Note aside that, whenever the almost superhuman skills of martial artists are depicted in films, they are either known to be blind (as, for example, Zatoichi), blinded in their ultimate fight (as, for example, Frank W. Dux in the lesser Bmovie Bloodsport), or they start to “see” in different, the mere phenomena transcending ways (like Matrix's hero Neo).

20 There have been recent journal articles on aesthetic experiences, art, and the beauty of martial arts, yet, none discusses specifically the possibility of the martial arts being a proprioceptive art: cf. (Elcombe 2012) and (Allen 2013).

${ }^{21}$ (Allen 2013: 251) makes a similar point.

22 I am indebted to Philipp Hübl for these suggestions.

${ }^{23}$ I thank an anonymous referee for that observation.

${ }^{24}$ Some practitioners of BDSM claim that their ritualised sexual acts are indeed an art form. I do not know whether arguments for that claim have been presented and/or whether "craft" rather than "art" is meant. Similarly we might think of the propagation of physical love and respective techniques Kuârnava- and Guhyasamaja Tantra are known for (cf. Eliade 1954/2004: 213-214). In any case, we should not forget that the erotic is often related to the beautiful.

${ }^{25}$ What about boxing, kick-boxing, wrestling, etc.? I have no good answer here. Some such sublimation of a sport that is commonly conceived as a mere physical exercise is offered by Yukio Mishima in his "Sun and Steel: Art, Action and Ritual Death" (1968). Japan's famous seppuku author took up weight lifting and reflects, in this autobiographical essay, upon martial arts, bodybuilding and the ways mind and body relate.

${ }^{26}$ I omit, for reasons of space, the important aspect that, through art appreciation, we gain access to Platonic Ideas (cf. Schopenhauer 1818: §50) and are faced with the awe-inspiring sublime. Will-less de-individualisation is, thus, achieved through perception of Platonic universals and confrontation with the sublime.

${ }^{27}$ Compare, for example, Patanjali's, i.e., Yoga's alleged founder's, Yoga-Sûtras 1.2 and 1.3: "Yoga is to still the patterning of consciousness"; "then, pure awareness can abide in its very nature". 